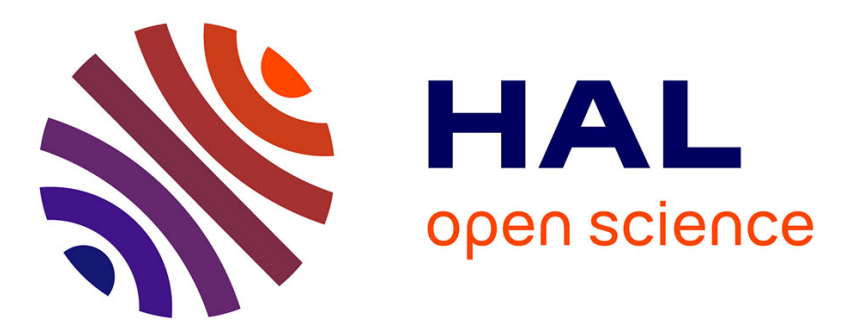

\title{
Quantitative calorimetry and TSA in case of low thermal signal and strong spatial gradients: Application to glass materials
}

G. Corvec, Eric Robin, Jean-Benoit Le Cam, Philippe Lucas, Jean-Christophe Sangleboeuf, F. Canevet

\section{- To cite this version:}

G. Corvec, Eric Robin, Jean-Benoit Le Cam, Philippe Lucas, Jean-Christophe Sangleboeuf, et al.. Quantitative calorimetry and TSA in case of low thermal signal and strong spatial gradients: Application to glass materials. Annual Conference and Exposition on Experimental and Applied Mechanics, Jun 2017, Indianapolis, United States. pp.13-19, 10.1007/978-3-319-62899-8_3 . hal-01695490

\section{HAL Id: hal-01695490 \\ https://hal-univ-rennes1.archives-ouvertes.fr/hal-01695490}

Submitted on 16 May 2020

HAL is a multi-disciplinary open access archive for the deposit and dissemination of scientific research documents, whether they are published or not. The documents may come from teaching and research institutions in France or abroad, or from public or private research centers.
L'archive ouverte pluridisciplinaire HAL, est destinée au dépôt et à la diffusion de documents scientifiques de niveau recherche, publiés ou non, émanant des établissements d'enseignement et de recherche français ou étrangers, des laboratoires publics ou privés. 


\title{
Quantitative Calorimetry and TSA in Case of Low Thermal Signal and Strong Spatial Gradients: Application to Glass Materials
}

\author{
Guillaume Corvec, Eric Robin, Jean-Benoît Le Cam, Pierre Lucas, Jean-Christophe Sangleboeuf, and \\ Frédéric Canevet
}

\begin{abstract}
In the present paper, the thermo-mechanical characterization of a holed glass sample under cyclic loading is carried out. Due to the low thermoelastic response obtained for such a material, the thermal movie has been preliminary filtered. The experimental stress field obtained from the Thermoelastic Stress Analysis (TSA) is well correlated to the finite element model. It validates both the use of this experimental technique to study the thermoelastic response of brittle materials and the filtering methodology. Finally, the corresponding calorimetric response has been determined by using a simplified formulation of the heat diffusion equation. This permits to quantify heat sources and to carry out energy balances.
\end{abstract}

Keywords Infrared thermography $•$ Denoising methodology - Inorganic oxide glass $・$ Thermoelastic stress analysis $\bullet$ Quantitative calorimetry

\subsection{Introduction}

The Thermoelastic Stress Analysis (TSA) [1,2] and the quantitative calorimetry are non-contact techniques, which have experienced an impressive expansion since the 1980s with the development of thermal cameras. They are used to access to the thermoelastic and the calorimetric effects accompanying the deformation of materials in order to better understand and model their mechanical behavior. Most materials have already benefited from these techniques including smart memory alloys [3], aluminum alloys [4], polymers [5], composites [6-10] and elastomers [11, 12]. These materials exhibit temperature variations in the range of one degree or more. In these conditions the experimental noise does not extensively affect the measurement and basic filters can be used to detect and to quantify temperature variations.

Concerning inorganic glasses, although these materials are used in a wide range of applications due to their transparency, heat resistance, pressure resistance, and chemical resistance, their fragility and low fracture toughness prevent them from use in most mechanical components. To understand or improve their mechanical behavior, most of the studies have been carried out on the crack tip movement [13], the mechanical properties [14] or fracture [15, 16], but rarely on their thermo-mechanical properties. A possible cause of this state is that the low strain level supported by glasses, combined with their low thermal conductivity, lead to very low temperature variations during the deformation process. Hence, to the best of authors knowledge, only two studies have been dedicated to the thermal and thermo-mechanical response of inorganic glasses [17, 18].

The aim of this paper is to present strong thermal gradients measurement at the surface of a holed disc in case of low temperature variation conditions, without altering the spatial resolution of the infrared images after the filtering process. The stress fields obtained by TSA are compared to a Finite Element Method model. As the mechanical behavior is well known under such tests conditions, this allows us to validate the presented denoising methodology. Then, quantitative calorimetry analysis is carried out by computing heat sources produced and absorbed from the temperature field measured at thespecimen

G. Corvec $(\bowtie) \cdot$ E. Robin • J.-B. Le Cam • J.-C. Sangleboeuf

Universitée de Rennes 1, Institut de Physique UMR 6251, CNRS/Université de Rennes 1, Campus de Beaulieu, Bât. 10B,

35042 Rennes Cedex, France

e-mail: guillaume.corvec@gmail.com

P. Lucas

Arizona Materials Laboratory, 4715 East Fort Lowell Rd, Tucson, AZ 85712, USA

F. Canevet

Cooper Standard France, 194 route de Lorient, 35043 Rennes, France 
surface. The methodology to identify intrinsic dissipation is given. The validation of this methodology at ambient temperature is a first step towards the use of thermal field measurements on glassy materials at temperatures close to glass temperature transition.

\subsection{Experimental Setup}

\subsubsection{Specimen Geometry and Testing Conditions}

The material considered here is a soda lime glass. The sample, presented in Fig. 3.1 corresponds to a disc of $2.1 \mathrm{~mm}$ in thickness and $29.7 \mathrm{~mm}$ in diameter with three elliptical holes. The major and minor axis lengths are respectively 6 and $3 \mathrm{~mm}$. The holes are oriented in relation to each other according to the major axis with an angle of $120^{\circ}$. The centre of the holes are $6 \mathrm{~mm}$ far from the disc center. The holes were cut with a water jet cutting machine. During the mechanical test, one of the holes was oriented with an angle of $27.91^{\circ}$ according to its major axis and the loading axis.

The disc was submitted to cyclic compressive loading by means of a 5543 Instron testing machine. An overview of the experimental setup is given in Fig. 3.1. The test was conducted under a prescribed periodic triangular signal. The minimum and maximum values of the compression force are $5 \mathrm{~N}$ and $520 \mathrm{~N}$, respectively. The sample was submitted to ten cycles at a frequency of $2.9 \mathrm{~Hz}$.

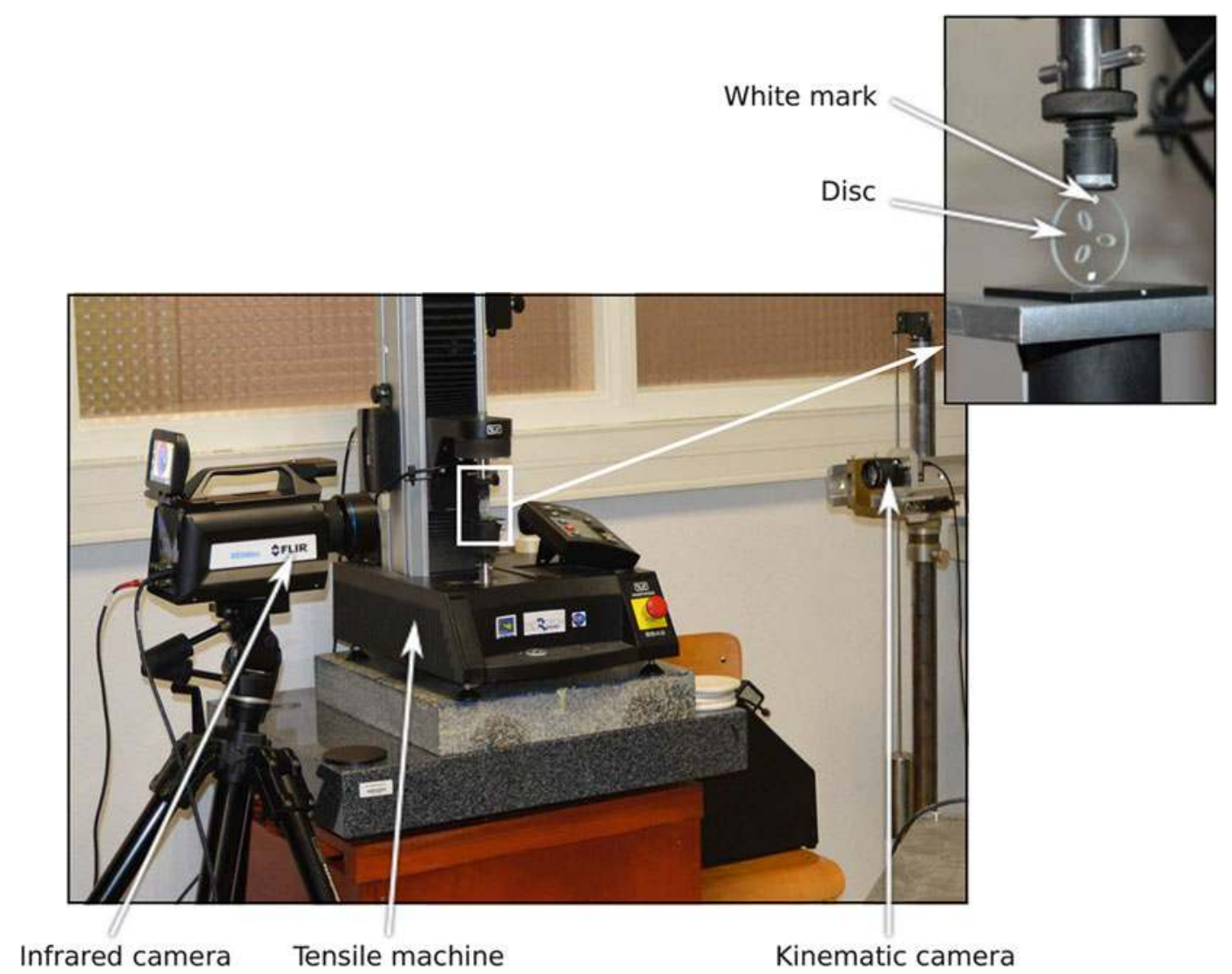

Fig. 3.1 Overview of the experimental setup 


\subsubsection{Thermal Measurement}

Temperature measurements were performed at ambient temperature using a X6540sc FLIR infrared camera. It features a focal plane array of $640 \times 512$ pixels and detectors with a wavelength in the range of 1.5-5.1 m. The integration time was equal to $1,000 \mathrm{~s}$ and the acquisition frequency was set at $100 \mathrm{fps}$. The manufacturer's protocol was used to perform the Non Uniformity Correction (NUC) of the camera. The resolution of the thermal measurement is equal to $20 \mathrm{mK}$ at $25^{\circ} \mathrm{C}$. The thermal emissivity of the material is close to 1 ( $>0.84$ for soda lime glass). By adding a converter, the spatial resolution of the thermal measurement was such that the size of the pixel was equal to $63 \mu \mathrm{m}$. The mechanical loading was applied after the specimen temperature stabilization and the start of the temperature measurement.

\subsection{Image Processing and Theoretical Background}

\subsubsection{Image Processing}

Thermal expansion coefficient and the brittleness of glasses are such that their thermal activity at ambient temperature when submitted to a mechanical loading remains low. This leads to noisy thermal signals. Therefore, filtering infrared images is required. To preserve the spatial resolution (i.e. no smoothing) when denoising the infrared images, a filtering methodology has been recently developed. The idea is to reduce the thermal movie spatio-temporal filter to a purely temporal approach, considering all the pixels independent from one another. From a general point of view, this method requires to track each material point to measure its temperature. However, in the case of inorganic glasses submitted to a mechanical loading, the deformation is sufficiently low to assume that the temperature measurements are not affected by the displacement of the material points observed by the camera at the sample surface. In the present study, this assumption was validated with the help of a mark tracking method. The results showed that the displacements of a tracked mark painted at the sample surface, in a zone where they are supposed to be the highest, were lower than the spatial resolution of the thermal camera. As the material elasticity is linear and that temperature variations are proportional to stress variations, temperature variation and displacement evolve in the same way. As displacement measurement is less noisy than temperature variation measurement, the characteristics of the denoising filter applied to the temperature variation field are defined from the spectral analysis of the displacement signal. The temperature variation field was filtered with a short time fast Fourier transform (STFFT) by selecting the background and the first two harmonics of the displacement signal. The residual offset of each pixel was then identified and removed by using physically motivated considerations. Further details are provided in [19].

\subsubsection{Thermoelastic Stress Analysis (TSA)}

The TSA approach permits to link temperature and stress variations. Stress variation corresponds to change in the sum of principal Cauchy stresses $\operatorname{tr}(\sigma)$, which corresponds to three times the hydrostatic stress. The thermomechanical framework of the TSA is described following the formalism introduced in [20]. Considering the heat diffusion equation in the case of a flat thin inorganic glass sample, the following assumptions can be made:

- The Fourier's law is used to model the heat conduction,

- The heat conduction is isotropic,

- The external heat sources, the density and the heat capacity are constant over the duration of the test,

- The intrinsic dissipation due to irreversibilities such as internal friction or damage are negligible.

These hypotheses lead to the fallowing equation:

$$
\Delta \theta=-\operatorname{Atr}(\sigma)
$$

where $\theta\left(=T-T_{r e f}\right)$ and $\operatorname{tr}(\sigma)$ are respectively the temperature variation and the sum of principal Cauchy stresses. The variables range is represented by the $\Delta$ symbol. $A$ is the so-called thermoelastic coefficient and is equal to $\alpha T_{0} / \rho C_{\mathrm{E}, \mathrm{V}_{\mathrm{k}}}$ where $\alpha$ is the thermal expansion coefficient, $T_{0}$ is the mean temperature of the specimen, $\rho$ is the density and $C_{\mathrm{E}, V_{\mathrm{k}}}$ the specific heat at constant $\mathrm{E}$ and $V_{k}$. E and $V_{k}$ are respectively the strain tensor and other internal variables. TSA gives rise to numerous 
applications in the field of thermoelastic stress analysis. The reader can refer to $[2,21]$ for further information. For the material considered in this study, parameter $A$ is equal to $1.34110^{-3} \mathrm{~K} / \mathrm{MPa}$ at $25^{\circ} \mathrm{C}$.

\subsubsection{Simplified Heat Diffusion Equation}

- Let us now assuming that no thermal conductivity occurs through the sample thickness,

- The loading frequency is sufficiently high to ensure quasi-adiabatic conditions, so that both conduction and convection can be neglected,

- The thermal diffusion length is lower than the spatial variations of stress in the disc,

- The ambient temperature remains constant during the test.

In such conditions, the heat diffusion equation is given by:

$$
\rho \mathrm{C}_{\mathrm{E}, \mathrm{V}_{\mathrm{k}}}\left(\dot{\theta}+\frac{\theta}{\tau}\right)=\mathrm{s}
$$

where $\tau$ is a time constant estimated by measuring the return to the thermal equilibrium of the material. To estimate heat sources $s$ produced by the material, the procedure consists in calculating the left-hand side of Eq. 3.2 by processing the temperature variation fields. It should be noted that intrinsic dissipation $\left(d_{l}\right)$ should be produced by the material. In this case the right hand side of Eq. 3.2 writes: $s+d_{l}$.

\subsection{Results and Discussion}

\subsubsection{Stress Field}

To determine the stress field from the temperature variation field, a short-time fast Fourier transform was used. The change of the sum of principal stresses was then calculated with the help of Eq. 3.1 applied at each pixel. It is signed using the following equation:

$$
\Delta \operatorname{tr}(\sigma)_{\text {signed }}=\Delta \operatorname{tr}(\sigma) \times\left(-\frac{|\theta|}{\theta}\right)
$$

A finite element model of the holed disc has been performed with Abaqus software. 38,277 finite elements C3D8R (52,084 nodes) have been used. The thickness of the disc has been discretized with 3 finite elements. The elastic parameters, Young modulus and Poisson coefficient, were set at $70 \mathrm{GPa}$ and 0.2 , respectively. A $520 \mathrm{~N}$ compressive loading was applied on the disc by the circular analytical surfaces. The numerical and experimental results are compared in Figs. 3.2 and 3.3. Figure 3.2 depicts the hydrostatic pressure field while Fig. 3.3 presents the value of the hydrostatic pressure along a section between the contact zones.

These results highlight the very good correlation between experimental and numerical approaches, both from spatial and quantitative point of view. Since the elastic mechanical behavior of materials is well known this validates the present experimental approach. This means that this denoising methodology could be used to characterize the non-predictable mechanical state at the surface of glasses under complex loading conditions, especially for temperature close to glass transition.

\subsubsection{Heat Source Field Reconstruction}

The heat source field has been reconstructed from temperature variation field and the simplified heat diffusion equation (see Eq. 3.2). Figure 3.4 presents the heat source map obtained for an image corresponding to a time when the heat sources reach a maximum. 
a

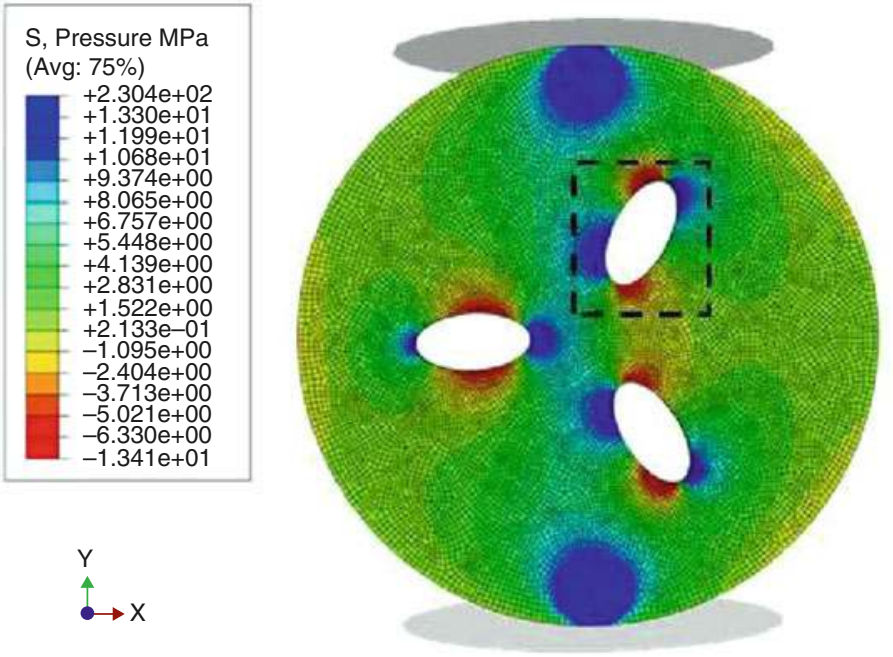

b

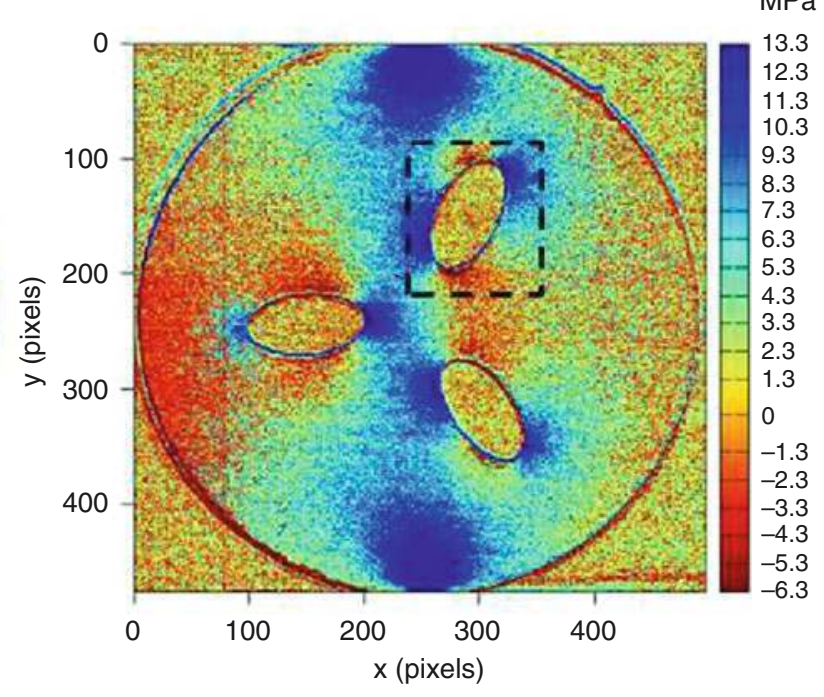

Fig. 3.2 Numerical (a) and experimental (b) fields of hydrostatic pressure

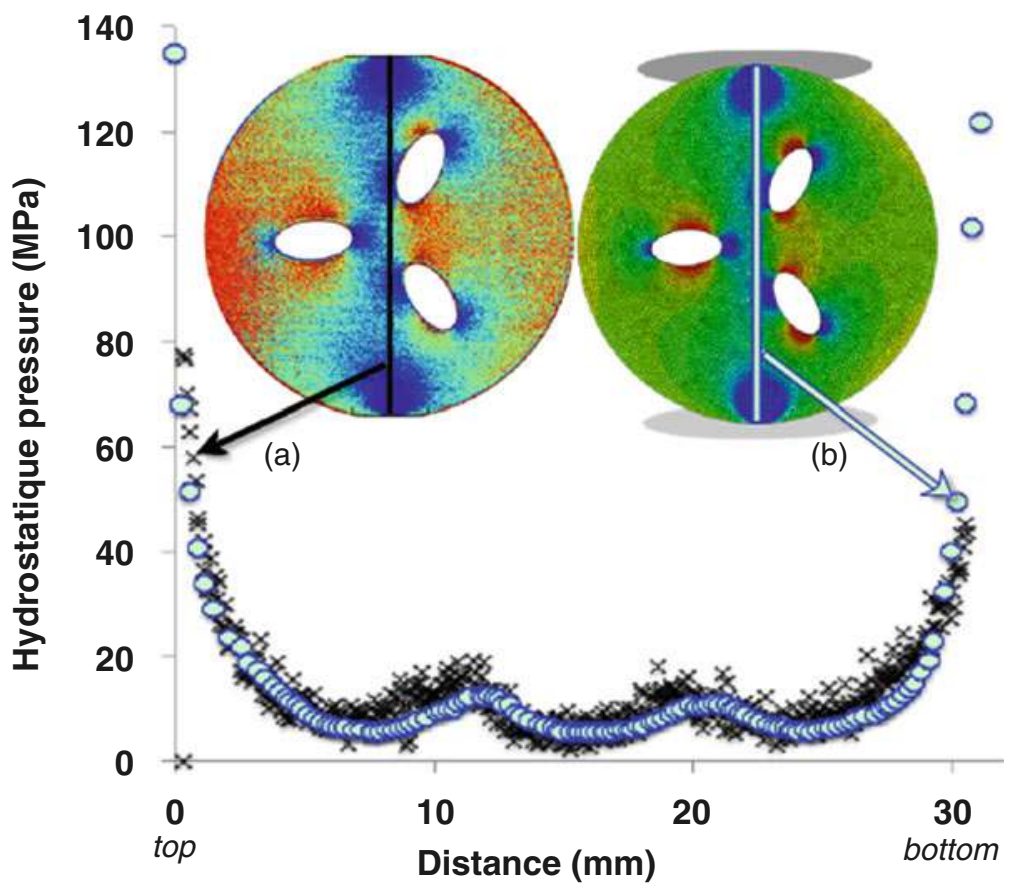

Fig. 3.3 Experimental (a) and numerical (b) value of the hydrostatic pressure along a profile defined between the contact zones

Figure 3.5a, b show the heat source variation at points A, B, C and D reported in Fig. 3.4. For each of them, heat sources oscillate around zero, meaning that no mechanical dissipation occurs. This is consistent with the fact that glass behaves as thermoelastic material at ambient temperature. The maximum value of the heat source is obtained at point A $\left(>1.5^{\circ} \mathrm{C} / \mathrm{s}\right)$, located in the contact zone. Point $\mathrm{D}$, located at the disc centre, far from the geometrical singularities induced by elliptical holes, exhibits very low heat source variations $\left(<0.25^{\circ} \mathrm{C} / \mathrm{s}\right)$. In the vicinity of one of the elliptical holes, at point B and C, the heat sources oscillate in phase but with opposite signs.

Results obtained in terms of heat source variation enable us to calculate the mechanical dissipation by subtracting the heat absorbed to the heat produced over one mechanical cycle. An average over several cycles can be done to increase the resolution of the calculation. Obviously in the present case, the mechanical dissipation was found to be nul, but the final aim is to apply this methodology to characterize the occurrence of mechanical dissipation when the ambient temperature is increased. 


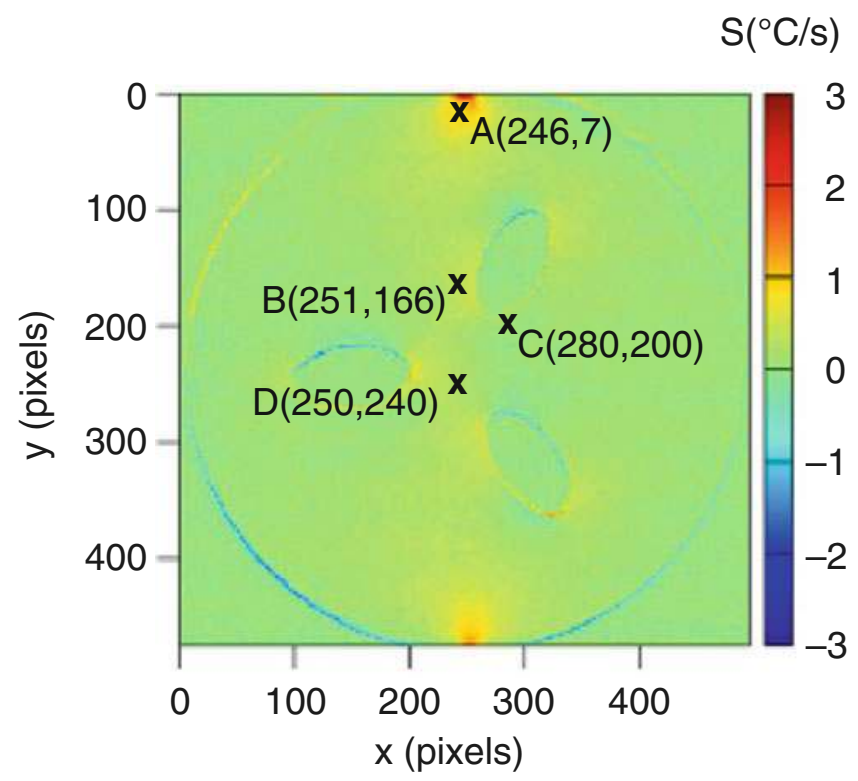

Fig. 3.4 Heat source field at a given time

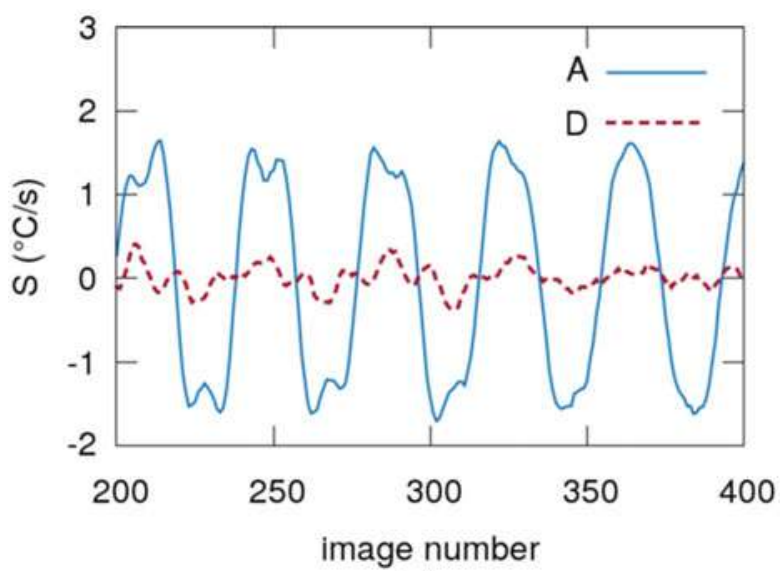

(a)

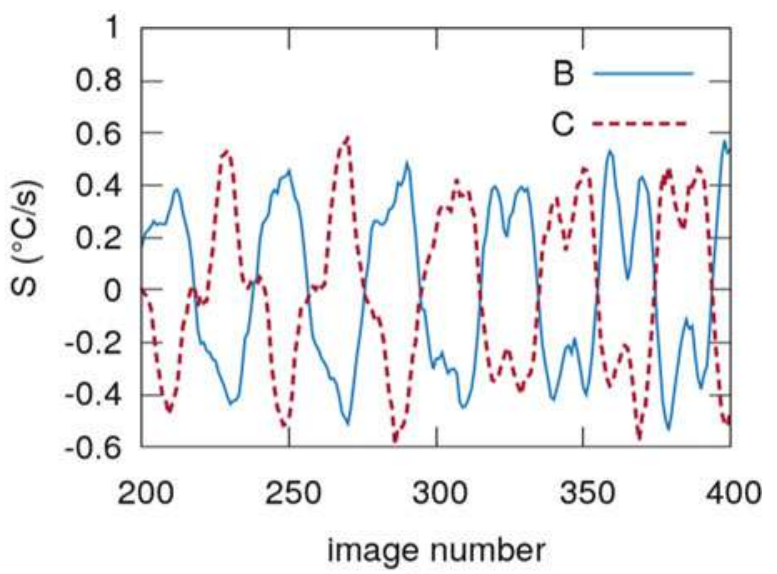

(b)

Fig. 3.5 Heat source variation (a) at points A and D (b) at points B and C

\subsection{Conclusions}

Thermomechanical characterization of a brittle material has been performed in the case of thermal signals of low amplitude and stress concentrations due to geometrical singularities. A disc of glass containing three elliptical holes has been submitted to a cyclic compressive load to investigate stress and strain concentration. Full thermal field measurement has been performed by using infrared thermography during cyclic loading. The temperature variation images stored during the test were denoised by using a methodology that permits to keep the spatial resolution equal to 1 . The framework of the TSA was applied to map the stress field at the surface of the specimen. Experimental results were quantitatively compared with numerical simulation issued from a finite element analysis, which serves as validation of the experimental methodology to process stresses from temperature measurements. Finally, the calorific response of the material has been determined from the heat diffusion equation and the temperature variation field. Its spatial resolution was also equal to 1 pixel. This method should permit to identify mechanical dissipation in case of complex loading conditions, i.e. for which no prediction is possible, as those encountered when the temperature is increased close to the glass transition temperature and the mechanical field is heterogeneous. 
Acknowledgements This work has received the financial support of AIS Scientific Grant from Rennes Métropole (2012), Mission of Resources and Skills Technology (MRCT) Grant from French National Center for Scientific Research (2012), Mission for Interdisciplinary(MI) Grant from French National Center for Scientific Research (2013), the Doctoral Politic Grant from Rennes 1 University.

\section{References}

1. Baker, L.R., Webber, J.M.B.: Thermoelastic stress analysis. Opt. Acta: Int. J. Opt. 29(4), 555-563 (1982)

2. Dulieu-Barton, J.M., Stanley, P.: Development and application of thermoelastic stress analysis. journal of strain analysisfor engineering design. J. Strain Anal. Eng. Des. 33, 93-104 (1998)

3. Chrysochoos, A., Licht, C., Peyroux, R.: Une modlisationthermomcanique unidimensionnelle de lapropagation d'un front de changement de phase dans un monocristal d'AMF. C. R. Mcanique. 331, 25-32 (2003)

4. Delpueyo, D., Balandraud, X., Grédiac, M.: Calorimetric signature of the Portevin-Le Chatelier effect in an aluminumalloy from infrared thermography measurements and heat source reconstruction. Mater. Sci. Eng: Struct. Mater. Prop. Microstruct. Process. 651, 135-145 (2016)

5. Chrysochoos, A.: Thermomechanical analysis of the cyclic behavior of materials. Procedia IUTAM. 4, 15-26 (2012)

6. Dulieu-Barton, J.M., Fruehmann, R.K., Quinn, S.: A full-field stress based damage assessment approach for in-situ inspection of composite structures. Key Eng. Mater. 569-570, 3-10 (2013)

7. Emery, T.R., Dulieu-Barton, J.M.: Thermoelastic stress analysis of damage mechanisms in composite materials. Compos. Pt. A-Appl. Sci. Manuf. 41, 1729-1742 (2010)

8. Fruehmann, R.K., Wang, W., Dulieu-Barton, J.M., Quinn, S.: The application of thermoelastic stress analysis to evaluate debond damage in composite sandwich structures. In: Advances in experimental mechanics Viii, vol. 70, pp. 470-475. Applied Mechanics and Material, Trans Tech Publications, Switzerland (2011)

9. Wang, W., Martakos, G., Dulieu-Barton, J.M., Andreasen, J.H., Thomsen, O.T.: Fracture behaviour at tri-materialjunctions of crack stoppers in sandwich structures. Compos. Struct. 133, 818-833 (2015)

10. Waugh, R.C., Dulieu-Barton, J.M., Quinn, S.: Modelling and evaluation of pulsed and pulse phase thermographythrough application of composite and metallic case studies. Ndt\& E Int. 66, 52-66 (2014)

11. Samaca Martinez, J.R., Le Cam, J.-B., Balandraud, X., Toussaint, E., Caillard, J.: Thermal and calorimetric effectsaccompanying the deformation of natural rubber. part 2: quantitative calorimetric analysis. Polymer. 54, 2727-2736 (2013)

12. Samaca Martinez, J.R., Le Cam, J.-B., Balandraud, X., Toussaint, E., Caillard, J.: Thermal and calorimetric effectsaccompanying the deformation of natural rubber. part 1: thermal characterization. Polymer. 54, 2717-2726 (2013)

13. Weichert, R., Schönert, K.: Heat generation at the crack tip of a moving crack. J. Mech. Phys. Solids. 26, 151-161 (1978)

14. Pouvreau, C., Drissi-Habti, M., Michel, K., Bureau, B., Sangleboeuf, J.-C., Boussard-Pledel, C., Rouxel, T., Adam, J.-L.: Mechanical properties of a tasfiber: a preliminary study. J. Non-Cryst. Solids. 316(1), 131-137 (2003)

15. Swain, M.V., Metras, J.C., Guillemet, C.G.: A deformation and fracture mechanics approach to the scoring and breaking of glass. J. Non-Cryst. Solids. 38-39(Part 1), 445-450 (1980)

16. Guin, J.-P., Wiederhorn, S.M.: Crack growth threshold in soda lime silicate glass: role of hold-time. J. Non-Cryst. Solids. 316(1), 12-20 (2003)

17. Le Cam, J.-B., Robin, E., Balandraud, X., Toussaint, E.: A new experimental route in thermomechanics of inorganic glasses using infrared thermography. J. Non-Cryst. Solids. 366, 64-69 (2013)

18. Robin, E., Le Cam, J.-B., Balandraud, X., Toussaint, E., Brilland, L.: First steps towards thethermomechanical characterization of chalcogenide glass using quantitative infrared thermography. J. NonCryst. Solids. 391, 101-105 (2014)

19. Corvec, G., Robin, E., Le Cam, J.-B., Sangleboeuf, J.-C., Lucas, P.: Improving spatio-temporal resolution of infraredimages to detect thermal activity of defect at the surface of inorganic glass. Infrared Phys. Technol. 77, 193-202 (2016)

20. Nguyen, Q.S., Germain, P., Suquet, P.: Continuum thermodynamics. J. Appl. Sci. 50, 1010-1020 (1983)

21. Sathon, N., Dulieu-Barton, J.M.: Evaluation of sub-surface stresses using thermoelastic stress analysis. Appl. Mech. Mater. 7/8, 153-158 (2007) 